\title{
Manganese-dependent regulation of the endocarditis-associated virulence factor EfaA of Enterococcus faecalis
}

\begin{abstract}
Correspondence
Anthony W. Smith

a.w.smith@bath.ac.uk
\end{abstract}

Received 31 July 2002

Accepted 22 October 2002

\author{
Yuen L. Low, ${ }^{1}$ Nicholas S. Jakubovics, ${ }^{2}$ Jennifer C. Flatman, ${ }^{1}$ \\ Howard F. Jenkinson ${ }^{2}$ and Anthony W. Smith ${ }^{1}$ \\ ${ }^{1}$ Department of Pharmacy and Pharmacology, University of Bath, Bath BA2 7AY, UK \\ ${ }^{2}$ Department of Oral and Dental Science, University of Bristol, Bristol BS1 2LY, UK
}

\begin{abstract}
There is increasing recognition of the emerging role of manganese regulation and acquisition in some pathogenic bacteria. Expression of the Enterococcus faecalis endocarditis-associated virulence factor $\mathrm{EfaA}$ is induced by growth in serum. It is demonstrated here that expression of the efaCBA operon encoding a putative $\mathrm{ABC}$-type transporter is regulated by $\mathrm{Mn}^{2+}$. Transcription of efaCBA and EfaA production were repressed in $\mathrm{Mn}^{2+}$-supplemented medium. $\mathrm{A} \mathrm{Mn}^{2+}$-responsive transcriptional regulator, EfaR, sharing $27 \%$ identity with the Corynebacterium diphtheriae diphtheria toxin repressor (DtxR), was identified. In the presence of $\mathrm{Mn}^{2+}$, EfaR protein bound in vitro to the efaC promoter region. Analysis of the $E$. faecalis $V 583$ genome revealed ten additional putative EfaR-binding sites, suggesting that manganese availability could have a broader regulatory role in infection. The results identify a new $\mathrm{Mn}^{2+}$-sensing regulator in enterococci that regulates the expression of a virulence factor implicated in enterococcal endocarditis.
\end{abstract}

\section{INTRODUCTION}

The importance of enterococci as pathogens, particularly in the nosocomial setting, is now widely recognized (Murray, 1990) and their increasing antibiotic resistance is narrowing options for treatment of serious infections (Landman \& Quale, 1997; Swartz, 1994). The enterococci, especially Enterococcus faecalis, are a leading cause of infective endocarditis, accounting for up to $20 \%$ of cases (Mylonakis \& Calderwood, 2001). Studies of E. faecalis strains revealed a dominant $37 \mathrm{kDa}$ antigen recognized by sera from patients with infective endocarditis (Aitchison et al., 1987). The endocarditis-specific expression of the $37 \mathrm{kDa}$ antigen was confirmed and exploited in a serodiagnostic ELISA, which successfully discriminated cases of $E$. faecalis endocarditis from endocarditis due to other streptococci and from other E. faecalis infections such as those in the urinary tract (Shorrock et al., 1990). The gene encoding this antigen has been cloned, sequenced and designated efaA (Lowe et al., 1995). Northern blot analysis indicated that its expression was induced by growth of the cells in medium supplemented with human serum (Lowe et al., 1995). Studies with a mouse model of peritoneal infection suggest that $\mathrm{EfaA}$ is a virulence factor (Singh et al., 1998). The efaA gene has since been found

Abbreviations: CBP, calmodulin-binding protein; EMSA, electrophoretic mobility shift assay.

The GenBank/EMBL/DDBJ accession number for the efaR gene sequence of $E$. faecalis $\mathrm{JH} 2-2$ reported in this paper is AF409093. to be the third gene of the efaCBA operon, likely encoding an ABC-type transporter, with EfaA being the lipoprotein component. Recent evidence indicates that some ABC-type transporters homologous to efaCBA are high-affinity permeases for divalent transition metal ions. For example, ScaCBA (Streptococcus gordonii; Kolenbrander et al., 1998) and MntCAB (Synechocystis sp. PCC 6803; Bartsevich \& Pakrasi, 1996) have been shown to transport $\mathrm{Mn}^{2+}$. In many cases, prokaryotic metal cation homeostasis is achieved by transcriptional regulation of genes encoding metal cation uptake proteins. Two main families of metalloregulators responsive to the divalent transition metal cations $\mathrm{Fe}^{2+}$, $\mathrm{Mn}^{2+}$ and/or $\mathrm{Zn}^{2+}$ have been recognized in Gram-positive bacteria: the Fur and DtxR families. Some members of the DtxR family have been shown to be manganese-dependent transcriptional repressors of $A B C$ metal ion permease operons homologous to efaCBA, e.g. ScaR (Streptococcus gordonii; Jakubovics et al., 2000) and MntR (Staphylococcus aureus; Horsburgh et al., 2002).

In this work, we have tested the hypothesis that efa $\mathrm{A}$ expression is manganese ion-dependent and regulated via a cation-dependent DtxR-like protein.

\section{METHODS}

Bacterial strains and growth conditions. The bacterial strains and plasmids used in this study are listed in Table 1. Enterococcal cultures were grown at $37^{\circ} \mathrm{C}$ without shaking in brain/heart infusion (BHI) 
Table 1. Strains, plasmids and oligonucleotides used in this study

Abbreviations: $\mathrm{Amp}^{\mathrm{R}}$, beta-lactam resistant; $\mathrm{Cam}^{\mathrm{R}}$, chloramphenicol resistant; $\mathrm{Nal}^{\mathrm{R}}$, nalidixic acid resistant; Tet $^{\mathrm{R}}$, tetracycline resistant.

\begin{tabular}{|c|c|c|}
\hline Component & Description & Source/reference \\
\hline \multicolumn{3}{|l|}{ Strains } \\
\hline Enterococcus faecalis $\mathrm{JH} 2-2$ & Wild-type, standard laboratory strain, plasmid-free & Jacob \& Hobbs (1974) \\
\hline E. coli XL-1 Blue & 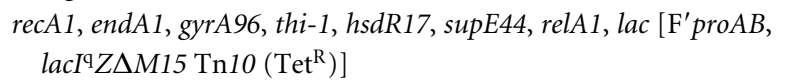 & Stratagene \\
\hline \multicolumn{3}{|l|}{ Plasmids } \\
\hline pGEM-T & PCR cloning vector, $\mathrm{Amp}^{\mathrm{R}}$ & Promega \\
\hline pGEM $: e f a C p$ & $\begin{array}{l}\text { pGEM-derived, contains } E \text {. faecalis efaC promoter region and } \\
\text { internal region of efaC for use as control }\end{array}$ & This study \\
\hline pCal-c & $\mathrm{Amp}^{\mathrm{R}}$, ColE1ori, calmodulin-binding peptide (CBP) & Stratagene \\
\hline YLL11F & 5'-CggggATccGTTTTCCTCACTTTCTCTAATCAACGG & efaR \\
\hline YLL11R & 5'-CgGgCtagcAATCGCGAAGACTATTTAAAATTAATT & efaR \\
\hline YLL14F & 5'-GgGgaAttcAAGCGCTTGTATTTAGGTGC & efaC promoter \\
\hline YLL14R & 5'-GgGgaaTTCTTTCTTTCCTGGGCGTTTTA & efaC promoter \\
\hline NSJ1F & 5'-AGCTGTTCAAGCGTTAACCG & efaC internal fragment \\
\hline NSJ1R & 5'-AATCACCTCAGCACCTTGGG & efaC internal fragment \\
\hline
\end{tabular}

* Bases in lower case indicate mismatched bases introduced into the oligonucleotides to create restriction enzyme sites (underlined).

broth (Oxoid) or tryptone/yeast extract/HEPES-buffered glucose (TYHG) medium [0.25\% (w/v) Bacto-tryptone (Difco), $0 \cdot 25 \%(\mathrm{w} / \mathrm{v})$ yeast extract, $0 \cdot 5 \%(\mathrm{w} / \mathrm{v})$ glucose and $25 \mathrm{mM}$ HEPES-NaOH, $\mathrm{pH} 7 \cdot 3$ ]. Metal ion depletion was achieved by adding Chelex-100 resin (Bio-Rad) to $80 \mathrm{~g} \mathrm{l}^{-1}$ and stirring overnight at $4{ }^{\circ} \mathrm{C}$. The medium was supplemented with $1 \mathrm{mM} \mathrm{MgCl}$ and $\mathrm{MnCl}_{2}, \mathrm{CuCl}_{2}, \mathrm{FeCl}_{3}, \mathrm{NiCl}_{2}$ and $\mathrm{ZnCl}_{2}$ were added to $10 \mu \mathrm{M}$ as appropriate. Glassware was treated by soaking overnight in $0.01 \%(\mathrm{w} / \mathrm{v})$ EDTA, followed by six rinses with MilliQ water.

DNA and RNA manipulations. Enterococcal chromosomal DNA was extracted from cells using the method of Skjold et al. (1987). Other procedures were performed according to the methods described by Sambrook et al. (1989). For Northern blot analysis, primers NSJ1F and NSJ1R (Table 1) were used to produce a $483 \mathrm{bp}$ internal fragment of efaC. RNA extraction and Northern blotting were performed as described previously (Jakubovics et al., 2000). The entire efaR coding region (672 bp; accession no. AF409093) was amplified using primers YLL11F and YLL11R (Table 1), ligated into pGEM-T (Promega) to produce pGEM : efaR and transformed into Escherichia coli DH5 $\alpha$. To produce recombinant EfaR protein, pGEM:efaR was digested and ligated into NheI- and Bam HI-digested pCal-c (Stratagene), generating pCal-c:efaR. This was transformed into E. coli BL21(DE3)pLysS and transformants were selected on LB agar containing ampicillin $(50 \mu \mathrm{g}$ $\mathrm{ml}^{-1}$ ). For gel-shift analysis, primers YLL14F and YLL14R (Table 1) were used. These span the $e f a C$ start site, identified by BLAST searching the unfinished and non-annotated sequence of the E. faecalis V583 chromosome at the TIGR website (http://www.tigr.org). The amplicon was cleaved with HincII to yield a $131 \mathrm{bp}$ target incorporating the $97 \mathrm{bp}$ upstream of the E. faecalis efaC start codon and a $212 \mathrm{bp}$ internal fragment for use as a control.

Sequencing and sequence analysis. Sequencing of plasmids constructed in this study was carried out at the automated DNA sequencing facility in the Department of Biology and Biochemistry at the University of Bath. Sequence analyses were performed using the Wisconsin Genetics Computer Group (GCG) software package. EfaB, EfaC and the E. faecalis DtxR-like protein EfaR were identified by BLAST search as described above. The BLAST search facilities of the National Library of Medicine, Washington, DC, USA (NCBI) were used to search for homologues.

Protein isolation and Western blotting. To extract surface proteins, enterococcal cells harvested in late exponential phase were digested in TE buffer with lysozyme $\left(0.2 \mathrm{mg} \mathrm{ml}^{-1}\right)$ for $10 \mathrm{~min}$ at $37^{\circ} \mathrm{C}$ and then vortexed with $0 \cdot 2 \mathrm{~g}$ glass beads $\left(\leqslant 10^{6} \mu \mathrm{m}\right.$; Sigma). After the beads had settled, the suspension was collected and unbroken cells were pelleted by centrifugation for $1 \mathrm{~min}$ at $8000 \mathrm{~g}$. The supernatant was recovered and centrifuged at $13000 \mathrm{~g}$ for $30 \mathrm{~min}$ at $4{ }^{\circ} \mathrm{C}$ to pellet the envelope fragments. Western blots of the envelope fragments separated by SDSPAGE on $10 \%(\mathrm{w} / \mathrm{v})$ polyacrylamide gels ( $10 \mu \mathrm{g}$ protein per lane) were probed with a $1: 50$ dilution of monospecific polyclonal rabbit antibodies to EfaA. The antiserum was raised in New Zealand White rabbits against EfaA protein. Rabbits were immunized with $100 \mathrm{mg}$ protein on days $1,7,14$ and 21 with alum as an adjuvant. Serum was collected on day 28. The protein had been expressed from pSK+: GP19 in E. coli XL-1 Blue (Lowe et al., 1995), separated by SDS-PAGE and electroeluted from the gel. The blots were visualized using anti-rabbit IgG conjugated 
to horseradish peroxide and enhanced chemiluminescence (ECL) according to the manufacturer's instructions (Amersham Life Science).

Purification of recombinant EfaR. LB broth was inoculated $1: 50$ from an overnight culture of E. coli BL21(DE3)pLysS cells harbouring pCal-c:efaR and shaken at 200 r.p.m., $37^{\circ} \mathrm{C}$ to an $\mathrm{OD}_{600}$ of $0 \cdot 5-0 \cdot 6$. IPTG was then added to $1 \mathrm{mM}$ and the cultures incubated for a further $3.5 \mathrm{~h}$. The cells were pelleted and resuspended in $15 \mathrm{ml} \mathrm{CaCl}_{2}$ binding buffer $(150 \mathrm{mM} \mathrm{NaCl}, 10 \mathrm{mM} \beta$-mercaptoethanol, $1 \mathrm{mM}$ magnesium acetate, $1 \mathrm{mM}$ imidazole, $2 \mathrm{mM} \mathrm{CaCl}_{2}, 0 \cdot 1 \mathrm{mM}$ PMSF, $50 \mathrm{mM}$ Tris/ $\mathrm{HCl}$, $\mathrm{pH} 8 \cdot 0)$. Lysozyme $\left(0 \cdot 2 \mathrm{mg} \mathrm{ml}^{-1}\right)$, RNase A $\left(10 \mu \mathrm{g} \mathrm{ml}^{-1}\right)$ and DNase I $\left(5 \mu \mathrm{g} \mathrm{ml}^{-1}\right)$ were added and the suspension was incubated with shaking at $4{ }^{\circ} \mathrm{C}$ for $15 \mathrm{~min}$, followed by sonication. Insoluble material was removed by centrifugation. Calmodulin-affinity resin (Stratagene) was used to purify the recombinant EfaR-calmodulin-binding peptide (EfaR-CBP) from the supernatant in accordance with the manufacturer's instructions. Following affinity-purification, the CBP tag was cleaved using thrombin and removed.

Electrophoretic mobility shift assay (EMSA). Target DNA fragments were labelled with $\left[\alpha-{ }^{32} \mathrm{P}\right] \mathrm{dATP}\left(6000 \mathrm{Ci} \mathrm{mmol}{ }^{-1}\right)$ using the Klenow fragment of DNA polymerase and EMSAs were performed as described previously (Jakubovics et al., 2000).

\section{RESULTS}

\section{Nucleotide and amino acid sequence analysis of efaCBA}

The entire nucleotide and amino acid sequences of the efaCBA operon have been compiled from the E. faecalis V583 chromosome at the TIGR website (http://www. tigr.org). The organization of the efa operon is depicted in Fig. 1(a). The efaA gene is the third of three genes, which sequence homology suggests encode an $\mathrm{ABC}$-type metal ion transport system. The first gene, efaC, encodes an ATPbinding protein (ATPase); the second, efaB, encodes a hydrophobic transmembrane protein. EfaA probably functions as a solute binding-protein receptor for the $\mathrm{ABC}$ complex. Within the region upstream of $e f a C$ are putative Shine-Dalgarno, -10 and -35 consensus sequences and two interrupted palindromic sequences of dyad symmetry that we have termed EfaR boxes (Fig. 1b).

EfaC possesses characteristics expected of ATP-binding proteins: a Walker A motif (GPNGAGKST; consensus is GXXGXGKST), the ABC family signature sequence (LSGG, identical to consensus), a Walker B motif (VIFLDEPF; consensus is hhhhDEPT, where $\mathrm{h}$ is any hydrophobic amino acid) and a 'switch' region (VGI; consensus is $\mathrm{xGh}$ ). CLUSTAL $\mathrm{W}$ analysis revealed that $\mathrm{EfaB}$ and $\mathrm{EfaC}$ are highly homologous to their Psa (Streptococcus pneumoniae; respectively 57 and $47 \%$ identical), Fim (Streptococcus parasanguis, 54 and $53 \%$ ) and Sca (55 and $51 \%$ identical) counterparts.

\section{EfaA expression and efaCBA transcription is manganese-regulated}

When E. faecalis JH2-2 cultures were grown in Chelex-

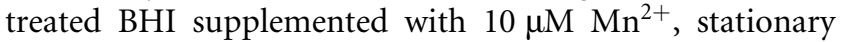
phase growth yields $\left(\mathrm{OD}_{600} 0 \cdot 94 \pm 0 \cdot 02\right)$ were increased by about $50 \%$ compared with unsupplemented medium (a)

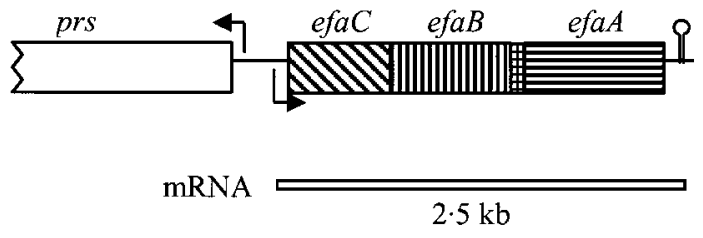

(b)

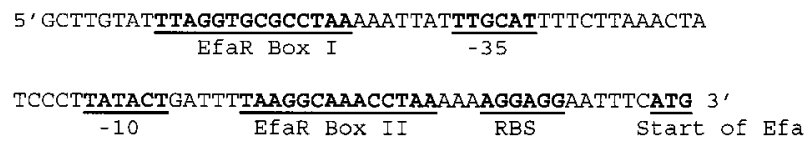

Fig. 1. (a) Schematic of the efaCBA locus in E. faecalis (not to scale). The efaB and efaA ORFs overlap by $14 \mathrm{bp}$. The transcript initiated from the efaC promoter terminates downstream of efaA ( $2.5 \mathrm{~kb})$. The divergently transcribed prs gene encodes a putative 5-phospho-Dribosyl- $\alpha$-1-pyrophosphate (PRPP) synthetase. (b) Nucleotide sequence of the efaCBA promoter region. Putative EfaR boxes, -35 and -10 elements, ribosome-binding site (RBS) and start codon are indicated.

$\left(\mathrm{OD}_{600} \quad 0 \cdot 637 \pm 0 \cdot 03\right)$. Supplementation with other metal cations tested $\left(\mathrm{Fe}^{3+}, \mathrm{Cu}^{2+}, \mathrm{Co}^{2+}, \mathrm{Ni}^{2+}\right.$ or $\left.\mathrm{Zn}^{2+}\right)$ at $10 \mu \mathrm{M}$ had no such effect $\left(\mathrm{OD}_{600} 0 \cdot 615 \pm 0 \cdot 01\right)$.

Western blot analyses of cell surface protein extracts from $E$. faecalis JH2-2 grown in Chelex-treated BHI supplemented with metal cations demonstrated that EfaA was strongly expressed in the absence of $\mathrm{Mn}^{2+}$. Addition of $10 \mu \mathrm{M} \mathrm{Mn}^{2+}$ to the growth medium repressed its expression (Fig. 2a). In contrast, addition of $10 \mu \mathrm{M} \mathrm{Fe}^{3+}, \mathrm{Co}^{2+}, \mathrm{Cu}^{2+}, \mathrm{Ni}^{2+}$ or $\mathrm{Zn}^{2+}$ did not affect EfaA production.

Northern analysis of total RNA from E. faecalis JH2-2 using an $e f a C$ probe revealed $e f a C B A$ to be transcribed as a single polycistronic transcript of approximately $2.5 \mathrm{~kb}$. In agreement with the Western blot data, the efaCBA transcript was strongly expressed when E. faecalis $\mathrm{JH} 2-2$ was grown in Chelex-treated broth. This transcript was repressed below detectable levels in $10 \mu \mathrm{M} \mathrm{Mn}{ }^{2+}$-supplemented medium (Fig. 2b). In contrast, supplementation with $\mathrm{Fe}^{3+}, \mathrm{Cu}^{2+}$, $\mathrm{Ni}^{2+}$ or $\mathrm{Zn}^{2+}$ had no apparent effect on the level of transcript production.

\section{Identification of EfaR and production of recombinant protein}

Examination of the region upstream of $E$. faecalis efaC revealed two inverted repeat sequences that closely resemble binding sequences for a number of metalloregulatory proteins, including DtxR (Corynebacterium diphtheriae; Lee et al., 1997), SirR (Staphylococcus epidermidis; Hill et al., 1998) and MntR (Staphylococcus aureus; Horsburgh et al., 2002). Hence, it was hypothesized that the manganese-regulation of efaCBA expression was mediated via a DtxR-like regulator. A DtxR homologue was identified in the E. faecalis V583 
(a)

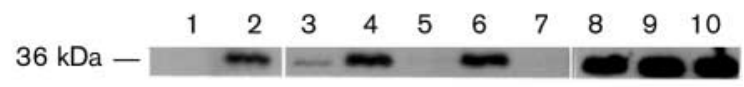

(b)

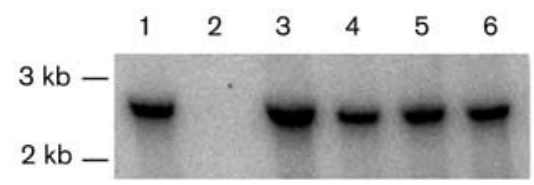

Fig. 2. (a) Western blot analysis of EfaA expression. Lanes: 1 and $2, E$. coli XL-1 Blue pSK+: GP19 before (lane 1) and after (2) IPTG induction; 3-10, E. faecalis JH2-2 grown in untreated $\mathrm{BHI}$ (3) or in Chelex-treated $\mathrm{BHI}$ and EDTA-treated glassware unsupplemented (4) or supplemented with $10 \mu \mathrm{M} \mathrm{Mn}^{2+}$ (5), $\mathrm{Fe}^{3+}$ (6), $\mathrm{Mn}^{2+}$ and $\mathrm{Fe}^{3+}$ (7), $\mathrm{Cu}^{2+}$ (8), $\mathrm{Ni}^{2+}$ (9) or $\mathrm{Zn}^{2+}$ (10). (b) Northern blot analysis of efaCBA transcription. Cells were cultured in Chelex-treated TYHG. RNA extracts (10 $\mu \mathrm{g}$ per lane) were probed with an internal fragment of efaC. $\mathrm{Mn}^{2+}$ (lane 2), $\mathrm{Fe}^{3+}$ (3), $\mathrm{Ni}^{2+}$ (4), $\mathrm{Cu}^{2+}$ (5) or $\mathrm{Zn}^{2+}$ (6) was added to $10 \mu \mathrm{M}$. Lane 1 contained no added metals.

chromosome at TIGR (http://www.tigr.org) and the sequence information used to clone the gene from $E$. faecalis JH2-2. The protein, designated EfaR (for Efa Regulator-ofexpression), comprises 222 amino acid residues with a predicted molecular mass of $25.5 \mathrm{kDa}$. The sequence of $\mathrm{EfaR}$ is $27 \%$ identical ( $45 \%$ similarity) to that of $C$. diphtheriae DtxR and $39 \%$ identical (56\% similarity) to Streptococcus gordonii ScaR.

The pCal-c vector (Stratagene) was chosen to produce recombinant EfaR. This plasmid enabled expression of the cloned protein as a fusion with a $4 \mathrm{kDa}$ C-terminal CBP tag. The CBP tag binds calmodulin with high affinity in the presence of low concentrations of calcium, facilitating recovery of the chimeric EfaR-CBP product by affinitypurification with calmodulin-affinity resin. The CBP tag contains a recognition site for the site-specific protease thrombin, releasing the recombinant protein without any C-terminal modification. After treatment with thrombin, purified EfaR with an apparent molecular mass of $26 \mathrm{kDa}$ was visualized by SDS-PAGE (Fig. 3).

\section{EfaR binds the efaC promoter in vitro in a metal- ion-dependent manner}

Despite the apparent high overall conservation of domain structure and metal-ion-binding residues across the DtxR family of proteins, the various DtxR homologues appear to have different and specific metal ion preferences in vivo, although purified DtxR homologues can bind a range of divalent transition metal cations in vitro (Hill et al., 1998; Jakubovics et al., 2000). Hence, a 131 bp DNA binding target, including $97 \mathrm{bp}$ upstream of the $e f a C$ translational start site and designated $e f a C p$, was incubated with $0-1 \cdot 0 \mu \mathrm{M}$ purified EfaR and $125 \mu \mathrm{M} \mathrm{Mn}^{2+}$ and a concentration-dependent shift

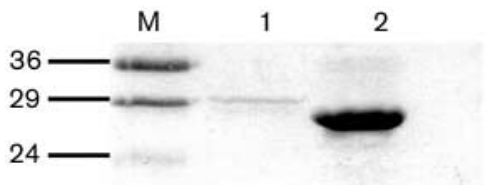

Fig. 3. SDS-PAGE of EfaR-CBP fusion protein and EfaR following cleavage of the CBP tag. An EfaR-CBP fusion protein was overexpressed in E. coli BL21(DE3)pLysS and purified using calmodulinaffinity resin. The CBP tag was cleaved with thrombin and removed by binding it to the affinity resin. EfaR protein was then concentrated using a Vivaspin column containing a filter with a 10000 Da molecular mass cut-off. The purified proteins were electrophoresed on a denaturing $10 \%(\mathrm{w} / \mathrm{v})$ polyacrylamide gel and stained with Coomassie blue. Lanes: $\mathrm{M}$, molecular mass marker (sizes in $\mathrm{kDa}$ ); 1 , purified EfaR-CBP; 2, purified and concentrated EfaR following cleavage of CBP.

was seen (Fig. 4a). Metal ion chelation with 1 mM EDTA (Fig. $4 \mathrm{~b}$ ) or competition with non-labelled efaCp (Fig. 4c) resulted in loss of shift. A number of other divalent metal cations were tested (Fig. 5); $\mathrm{Ni}^{2+}, \mathrm{Zn}^{2+}, \mathrm{Co}^{2+}$ and $\mathrm{Cu}^{2+}$ also caused $\mathrm{EfaR}$ to retard DNA migration. There was no shift when the EfaR promoter region was tested, indicating that the gene is not autoregulated (data not shown).

\section{DISCUSSION}

Divalent transition metal ions such as $\mathrm{Mn}^{2+}, \mathrm{Fe}^{2+}$ and $\mathrm{Zn}^{2+}$ are essential for both the growth and survival of microorganisms. Amongst other things, $\mathrm{Mn}^{2+}$ is important as a cofactor for many enzymes (Jakubovics \& Jenkinson, 2001) and is emerging as a regulator of oxidative stress regulons, for example in Staphylococcus aureus (Horsburgh et al., 2001) and Streptococcus gordonii (Jakubovics et al., 2002).

Expression of EfaA has previously been shown to be induced by growth of $E$. faecalis in medium containing serum (Lowe et al., 1995). Analysis of the E. faecalis V583 genome shows that EfaA is the third component of a trigenic operon homologous to ATP-binding cassette transporters that, in other micro-organisms, have been shown to transport $\mathrm{Mn}^{2+}$, e.g. ScaCBA of Streptococcus gordonii (Jakubovics et al., 2000) and MntCAB of Synechocystis sp. PCC 6803 (Bartsevich \& Pakrasi, 1996). We propose that EfaCBA is a manganeseregulated operon that likely functions as a high-affinity manganese permease in E. faecalis, possibly playing a role in the infection of human host tissues, where $\mathrm{Mn}^{2+}$ availability can be as low as $20 \mathrm{nM}$ (Krachler et al., 1999). Expression of a $\mathrm{Mn}^{2+}$ transporter would be expected to be responsive to $\mathrm{Mn}^{2+}$ availability in the growth medium, i.e. $\mathrm{Mn}^{2+}$ would regulate efaCBA expression. Western and Northern blot analyses are consistent with this hypothesis: the addition of $10 \mu \mathrm{M} \mathrm{Mn}^{2+}$ to the medium suppressed EfaA expression and efaCBA transcription. The increase in yield of E. faecalis $\mathrm{JH} 2-2$ cultures when grown in $\mathrm{Mn}^{2+}$-supplemented Chelex-treated BHI also indicated that $\mathrm{Mn}^{2+}$ is an important micronutrient for this micro-organism. These 
(a)

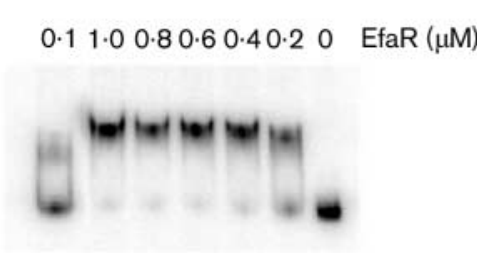

(b)

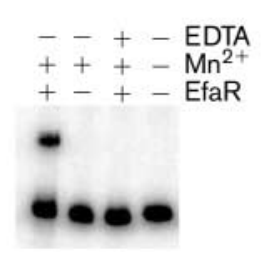

(c)

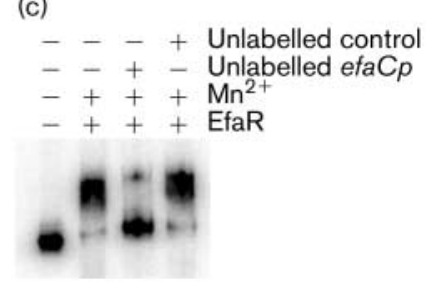

Fig. 4. EMSA of EfaR binding to the upstream region of efaC (efaCp). (a) Effect of EfaR concentration. Purified EfaR was incubated with $\alpha^{-32} \mathrm{P}$-labelled efaCp and $125 \mu \mathrm{M} \mathrm{Mn}^{2+}$. (b) Effect of EDTA on EfaR binding to efaCp. $\alpha^{-32} \mathrm{P}$-labelled efaCp was incubated with $1 \mu \mathrm{M} \mathrm{EfaR}, 125 \mu \mathrm{M} \mathrm{Mn}^{2+}$ and $1 \mathrm{mM}$ EDTA. (c) Competition with unlabelled efaCp. Purified EfaR ( $\left.1 \mu \mathrm{M}\right)$ was incubated with $\alpha^{-32} \mathrm{P}^{-}$ labelled efaCp and $125 \mu \mathrm{M} \mathrm{Mn}^{2+}$. Ten $\mu$ g unlabelled efaCp (lane 3) and $10 \mu$ g unlabelled control fragment (lane 4) were included.

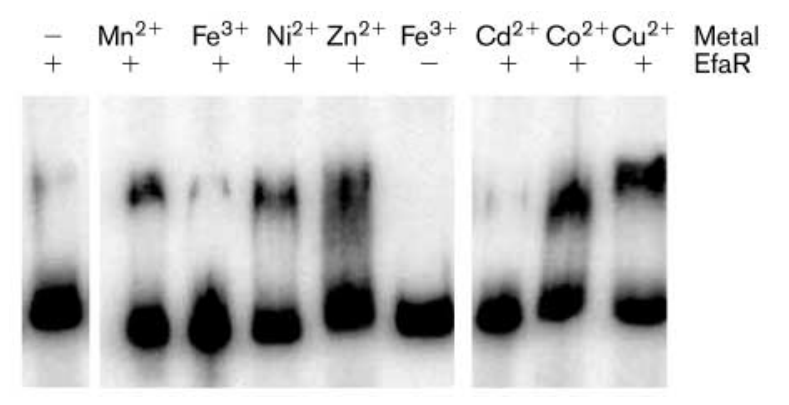

Fig. 5. Effect of metal cations on EfaR binding to efaCp. Purified EfaR $(1 \mu \mathrm{M})$ was incubated with $\alpha^{-32}$ P-labelled efaCp and $125 \mu \mathrm{M}$ metal cation.

results suggest that the previously observed serum-mediated induction was likely due to sequestration of $\mathrm{Mn}^{2+}$ from the growth medium by components present in serum. Total manganese levels in BHI medium have been estimated to be approximately $26 \mu \mathrm{M}$ and equilibrium dialysis measurements suggest that only $5 \mu \mathrm{M}$ is free (Tseng et al., 2001). Levels of available manganese in serum are typically around $20 \mathrm{nM}$, as most available manganese is complexed with albumin and transferrin (Krachler et al., 1999).

Expression of several efaCBA homologues has been shown to be governed by metal-dependent transcriptional regulators belonging to the DtxR family, e.g. in the presence of $\mathrm{Mn}^{2+}$, Streptococcus gordonii scaCBA transcription is repressed by the DtxR-like protein ScaR (Jakubovics et al., 2000), while Staphylococcus aureus mntABC is similarly repressed by MntR (Horsburgh et al., 2002). The archetype of the family, C. diphtheriae DtxR, has been shown to bind to $19 \mathrm{bp}$ palindromic elements with the sequence TTAGGTTAGCCTAACCTAA (Lee et al., 1997). The DtxR consensus binding sequence box 1 is better conserved in the promoter of the $E$. faecalis efaCBA operon than in the promoters of streptococcal homologues (Jakubovics et al., 2000). In fact, the putative binding sequence EfaR box 1, upstream of efaCBA, more closely resembles those present in the staphylococci (Hill et al., 1998; Horsburgh et al., 2002) than the $19 \mathrm{bp} \mathrm{C.}$ diphtheriae consensus binding sequence in that they lack the central five bases of the consensus sequence. Interestingly, reassessment of the $19 \mathrm{bp}$ motif indicates that it is the result of a repeated CCTAA motif on a $14 \mathrm{bp}$ palindrome.

The results of our EMSAs support the hypothesis that EfaR regulates expression of efaCBA. EfaR bound to DNA fragments containing the promoter region of $e f a C$ but not to non-specific DNA. The various DtxR homologues appear to be specific for either manganese or iron in vivo yet, as in this work, most have been observed to bind a range of metal cations in vitro (Hill et al., 1998; Jakubovics et al., 2000).

By searching the E. faecalis V583 genome for the 14-bp consensus TTAGGNNNCCTAA derived from the EfaR boxes upstream of $e f a C$, we have identified potential EfaR boxes in the promoter regions of several genes (Table 2). For example, EfaR boxes were present upstream of the two genes encoding natural resistance-associated macrophage protein (NRAMP) homologues. A similar search in the Mycobacterium tuberculosis database yielded over 40 different genes containing putative $19 \mathrm{bp}$ DtxR-like binding sequences (Gold et al., 2001). However, M. tuberculosis has two DtxRlike proteins, compared with one in E. faecalis. In addition to regulating metal ion transport, $C$. diphtheriae DtxR also regulates expression of virulence genes, the products of which include adhesins and a toxin (Tao et al., 1994). Hence, like DtxR, EfaR may well have a global regulatory role.

Whilst metal ions such as $\mathrm{Mn}^{2+}, \mathrm{Fe}^{2+}$ and $\mathrm{Zn}^{2+}$ are essential for many micro-organisms, they can also be potentially toxic at high concentrations. Hence, careful regulation of intracellular concentrations of such cations is essential. Here, we envisage that, in E. faecalis, EfaCBA is an ABC-type manganese permease regulated by EfaR, with $\mathrm{Mn}^{2+}$ acting as a corepressor. Accordingly, when $\mathrm{Mn}^{2+}$ is abundant, intracellular $\mathrm{Mn}^{2+}$ levels rise, resulting in the formation of EfaR$\mathrm{Mn}^{2+}$ complexes that bind the efaC promoter, inhibiting transcription and hence reducing $\mathrm{Mn}^{2+}$ uptake. When $\mathrm{Mn}^{2+}$ is scarce or its availability is restricted, e.g. in human serum, the EfaR apoprotein cannot bind the efaC promoter, derepressing efaCBA expression and hence increasing Efa permease levels and $\mathrm{Mn}^{2+}$ scavenging. Attempts to provide supporting genetic evidence have been frustrated by our 
Table 2. E. faecalis V583 genes possibly containing EfaR boxes upstream of ORF regions designated by EF loci

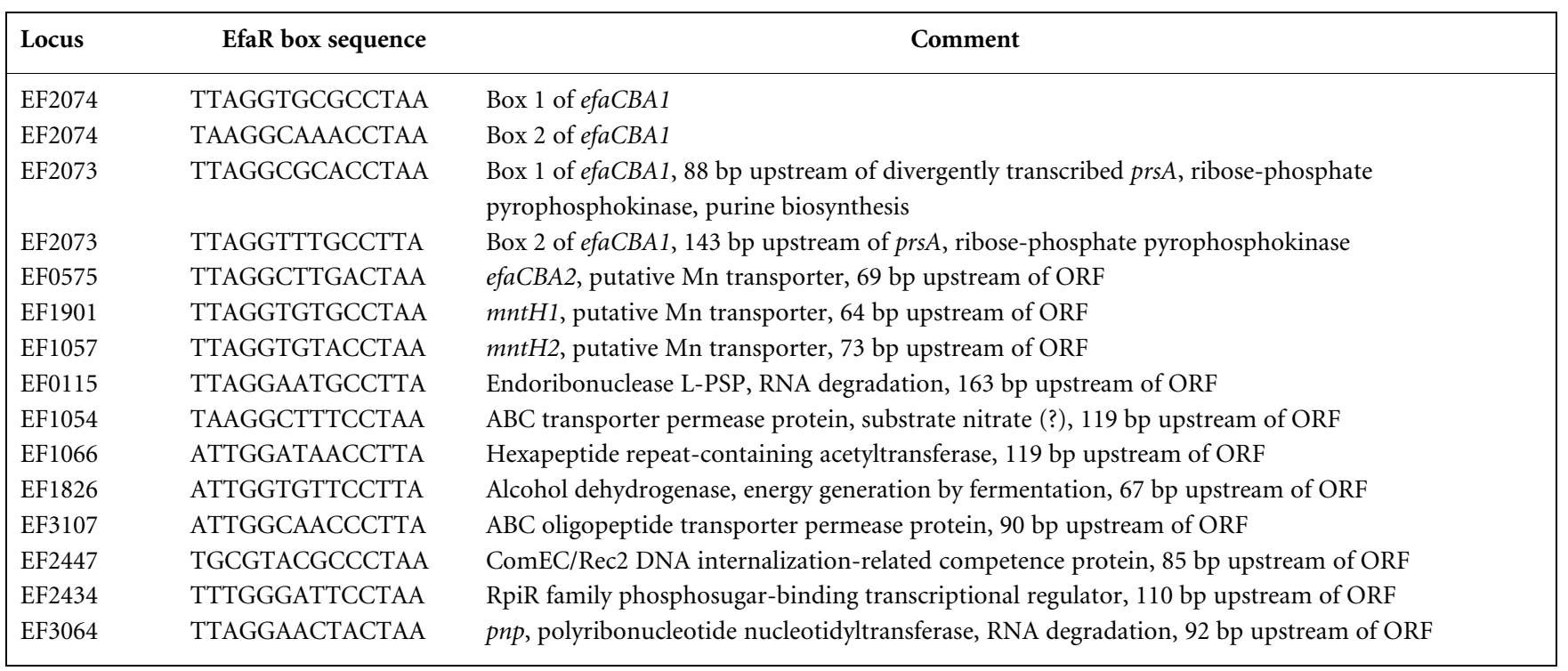

inability to generate mutants either in the efaCBA operon or efaR, despite extensive attempts using both allelic replacement and insertion duplication strategies.

In summary, little has been reported about enterococcal metal requirements. Here, we demonstrate that expression of the endocarditis-associated virulence factor EfaA is manganese-regulated. We have also identified a metalloprotein that binds to the promoter region of the efaCBA operon in a $\mathrm{Mn}^{2+}$-dependent manner and therefore likely mediates the manganese-dependent repression of the efaCBA operon in vivo. Sequences similar to the DtxR consensus binding sequence are also present upstream of several other enterococcal genes, suggesting that EfaR could represent a new paradigm for metalloregulation in the enterococci. The induction of EfaA expression by serum (Lowe et al., 1995) highlights the fact that serum could impose more than just restricted iron availability, and sequestration of other transition metal cations, such as manganese, is also important.

\section{ACKNOWLEDGEMENTS}

Y.L.L. was supported by the Redwood Scholarship from the Royal Pharmaceutical Society of Great Britain and an Overseas Research Scholarships award. The work was funded by the British Heart Foundation grant no. PG/97181. Preliminary E. faecalis V583 chromosomal sequence data were kindly provided by the Institute for Genomic Research (TIGR, http://www.tigr.org). Sequencing of the E. faecalis V583 chromosome was accomplished by TIGR with support from the National Institute of Allergy and Infectious Diseases. We gratefully acknowledge the BLAST search facilities of the NCBI (National Library of Medicine, Washington, DC).

\section{REFERENCES}

Aitchison, E. J., Lambert, P. A., Smith, E. G. \& Farrell, I. D. (1987). Serodiagnosis of Streptococcus faecalis endocarditis by immunoblotting of surface protein antigens. J Clin Microbiol 25, 211-215.

Bartsevich, V. V. \& Pakrasi, H. B. (1996). Manganese transport in the cyanobacterium Synechocystis sp. PCC 6803. J Biol Chem 271, 26057-26061.

Gold, B., Rodriguez, G. M., Marras, S. A. E., Pentecost, M. \& Smith, I. (2001). The Mycobacterium tuberculosis IdeR is a dual functional regulator that controls transcription of genes involved in iron acquisition, iron storage and survival in macrophages. Mol Microbiol 42, 851-865.

Hill, P. J., Cockayne, A., Landers, P., Morrissey, J. A., Sims, C. M. \& Williams, P. (1998). SirR, a novel iron-dependent repressor in Staphylococcus epidermidis. Infect Immun 66, 4123-4129.

Horsburgh, M. J., Clements, M. O., Crossley, H., Ingham, E. \& Foster, S. J. (2001). PerR controls oxidative stress resistance and iron storage proteins and is required for virulence in Staphylococcus aureus. Infect Immun 69, 3744-3754.

Horsburgh, M. J., Wharton, S. J., Cox, A. G., Ingham, E., Peacock, S. \& Foster, S. J. (2002). MntR modulates expression of the PerR regulon and superoxide resistance in Staphylococcus aureus through control of manganese uptake. Mol Microbiol 44, 1269-1286.

Jacob, A. E. \& Hobbs, S. J. (1974). Conjugal transfer of plasmid-borne multiple antibiotic resistance in Streptococcus faecalis var. zymogenes. J Bacteriol 117, 360-372.

Jakubovics, N. S. \& Jenkinson, H. F. (2001). Out of the iron age: new insights into the critical role of manganese homeostasis in bacteria. Microbiology 147, 1709-1718.

Jakubovics, N. S., Smith, A. W. \& Jenkinson, H. F. (2000). Expression of the virulence-related Sca $\left(\mathrm{Mn}^{2+}\right)$ permease in Streptococcus gordonii is regulated by a diphtheria toxin metallorepressor-like protein ScaR. Mol Microbiol 38, 140-153.

Jakubovics, N. S., Smith, A. W. \& Jenkinson, H. F. (2002). Oxidative stress tolerance is manganese $\left(\mathrm{Mn}^{2+}\right)$ regulated in Streptococcus gordonii. Microbiology 148, 3255-3263. 
Kolenbrander, P. E., Andersen, R. N., Baker, R. A. \& Jenkinson, H. F. (1998). The adhesion-associated sca operon in Streptococcus gordonii encodes an inducible high-affinity ABC transporter for $\mathrm{Mn}^{2+}$ uptake. J Bacteriol 180, 290-295.

Krachler, M., Rossipal, E. \& Micetic-Turk, D. (1999). Concentrations of trace elements in sera of newborns, young infants, and adults. Biol Trace Elem Res 68, 121-135.

Landman, D. \& Quale, J. M. (1997). Management of infections due to resistant enterococci: a review of therapeutic options. J Antimicrob Chemother 40, 161-170.

Lee, J. H., Wang, T., Ault, K., Liu, J., Schmitt, M. P. \& Holmes, R. K. (1997). Identification and characterization of three new promoter/operators from Corynebacterium diphtheriae that are regulated by the diphtheria toxin repressor (DtxR) and iron. Infect Immun 65, 4273-4280.

Lowe, A. M., Lambert, P. A. \& Smith, A. W. (1995). Cloning of an Enterococcus faecalis endocarditis antigen: homology with adhesins from some oral streptococci. Infect Immun 63, 703-706.

Murray, B. E. (1990). The life and times of the enterococcus. Clin Microbiol Rev 3, 46-65.

Mylonakis, E. \& Calderwood, S. B. (2001). Infective endocarditis in adults. $N$ Engl J Med 345, 1318-1330.
Sambrook, J., Fritsch, E. F. \& Maniatis, T. (1989). Molecular Cloning: $a$ Laboratory Manual, 2nd edn. Cold Spring Harbor, NY: Cold Spring Harbor Laboratory.

Shorrock, P. J., Lambert, P. A., Aitchison, E. J., Smith, E. G., Farrell, I. D. \& Gutschik, E. (1990). Serological response in Enterococcus faecalis endocarditis determined by enzyme-linked immunosorbent assay. J Clin Microbiol 28, 195-200.

Singh, K. V., Coque, T. M., Weinstock, G. M. \& Murray, B. E. (1998). In vivo testing of an Enterococcus faecalis efaA mutant and use of efaA homologs for species identification. FEMS Immunol Med Microbiol 21, 323-331.

Skjold, S. A., Quie, P. G., Fries, L. A., Barnham, M. \& Cleary, P. P. (1987). DNA fingerprinting of Streptococcus zooepidemicus (Lancefield group C) as an aid to epidemiological study. J Infect Dis 155, 1145-1150.

Swartz, M. N. (1994). Hospital-acquired infections: diseases with increasingly limited therapies. Proc Natl Acad Sci U S A 91, 2420-2427.

Tao, X., Schiering, N., Zeng, H. Y., Ringe, D. \& Murphy, J. R. (1994). Iron, DtxR, and the regulation of diphtheria toxin expression. Mol Microbiol 14, 191-197.

Tseng, H. J., Srikhanta, Y., McEwan, A. G. \& Jennings, M. P. (2001). Accumulation of manganese in Neisseria gonorrhoeae correlates with resistance to oxidative killing by superoxide anion and is independent of superoxide dismutase activity. Mol Microbiol 40, 1175-1186. 